\title{
Synthesis of genistein-containing star-shaped homo- and copolyesters by the ring-opening polymerization
}

\author{
Ewa Oledzka
}

Received: 30 October 2012/Revised: 22 February 2013/Accepted: 30 April 2013/

Published online: 10 May 2013

(C) The Author(s) 2013. This article is published with open access at Springerlink.com

\begin{abstract}
A novel initiator, naturally occurring in soy, has been developed for a direct synthesis of aliphatic star-shaped homo- and copolyesters. The synthesis is based on one of several known isoflavones, genistein, which has been employed as an initiator of homopolymerization of poly(L-Lactide) or co-initiator of copolymerization of $\varepsilon$-caprolactone and L-Lactide with $\mathrm{Sn}(\mathrm{Oct})_{2}$ as a catalyst. The nontoxic chemicals used allow for an inexpensive and safe for human body facile synthesis of biocompatible functionalized polymers suitable for medical and pharmaceutical applications. The obtained polymers were characterized by ${ }^{1} \mathrm{H},{ }^{13} \mathrm{C}$ NMR, FT-IR, SEC-MALLS and MALDI-TOF MS analysis.
\end{abstract}

Keywords Biodegradable polymers · Genistein - Natural initiator $\cdot$ Star-shaped polymers · Drug delivery systems

\section{Introduction}

Considerable interest exists in the synthesis of aliphatic homo- and copolyesters for their potential applications as biomedical materials, such as controlled drug delivery systems, surgical sutures and internal bone fixation [1-4]. Poly(L-Lactide) (PLA) and poly ( $\varepsilon$-caprolactone) (PCL) as well as their copolymers are the most extensively studied, characterized and used as biomedical materials due to their biodegradability, biocompatibility and permeability [5, 6]. Polyesters with well-defined architectures such as star-shaped, comb-like and dendritic polymers with controlled chain

Electronic supplementary material The online version of this article (doi:10.1007/s00289-013-0973-5) contains supplementary material, which is available to authorized users.

E. Oledzka $(\square)$

Department of Inorganic and Analytical Chemistry, Faculty of Pharmacy, Medical University of Warsaw, Banacha 1, Warsaw 02-097, Poland e-mail: eoledzka@wum.edu.pl 
numbers and lengths are attracting interest because they can modify structures and physical properties of PLA and PCL (e.g., their high degree of crystallinity) [7, 8]. These homo- and copolymers are usually synthesized by the ring-opening polymerization (ROP) and copolymerization of L-Lactide (LLA) or $\varepsilon$-caprolactone (CL) in the presence of multifunctional initiators containing hydroxyl or amine groups.

In recent years, many approaches have been made to optimize the properties of the obtained polymers, such as their bioactivity and biocompatibility, to satisfy the requirements of specific biomedical applications. A promising example is incorporation of bioactive or biocompatible hormones, peptides, amino acids, lipids and other natural compounds into the polymer chain [9-12]. Recently, Dong and coworkers investigated the synthesis, crystallization and morphology of six-arm starshaped PCL obtained by the ROP of CL with dipentaerythritol as the initiator in bulk [13]. In their laboratory, polypseudorotaxanes composed of star-shaped porphyrincored PCL and $\alpha$-cyclodextrin as well as a new class of linear-dendron-like PCL- $b$ poly(ethylene oxide) copolymers have also been successfully synthesized and characterized in detail $[14,15]$. Furthermore, Cho et al. [16] studied the details of the synthesis of star-shaped, amphiphilic block copolymers composed of fully degradable PCL by initiation with pentaerythritol, while Cui et al. [17] reported the synthesis and characterization of copolymers of CL and LLA using cyclotriphosphazene core. As an extension, star-shaped PCLs with PAMAM dendrimer core have been successfully synthesized and characterized in our laboratory [18].

Genistein (Gns) is one of the isoflavones that can be found in soy [19]. Recently, it has been reported that this compound has weak estrogenic and antiestrogenic properties, is an antioxidant, inhibits topoisomerase II and angiogenesis and induces cell differentiation [19]. Furthermore, it has been found that Gns promotes cell differentiation resulting in a less active epidermal growth factor signaling pathway in adulthood that, in turn, suppresses the development of mammary cancer [20].

As a matter of fact, it can also be a suitable material for the synthesis of starshaped polymers due to the presence of three hydroxyl groups in the molecule, enabling the initiation of ROP of LLA or CL. Therefore, it is reasonable to prepare homo- and copolymers with the desired biomedical properties inherited from the Gns molecule. In the ongoing study, biodegradable and biocompatible PLA homopolymers and random copolymers of LLA and CL were synthesized and characterized using for the first time naturally occurring Gns as a core. The influence of the Gns molecule on the thermal properties and hydrolysis stability of the obtained polyesters, as well as the release profile of the covalently conjugated drug to the resulting polymers, will be discussed in the next paper.

\section{Experimental}

\section{Materials}

$\varepsilon$-Caprolactone (2-oxepanone, $\geq 99.0 \%$, Aldrich Co. Poland) was dried and distilled before use over $\mathrm{CaH}_{2}$ at reduced pressure. L-Lactide ((3S)-cis-3,6-dimethyl-1,4-dioxane2,5-dione, $98.0 \%$, Aldrich Co. Poland) was recrystallized from dried ethyl acetate in a 
dry nitrogen atmosphere and then thoroughly dried in vacuum before use. Genistein (Gns, 5,7-dihydroxy-3-(4-hydroxyphenyl)-4H-1-benzopyran-4-one, $\geq 98 \%$, Sigma Co. Poland) was dried before use under vacuum at $40{ }^{\circ} \mathrm{C}$ for $4 \mathrm{~h}$. Stannous octoate ( $\mathrm{Sn}(\mathrm{Oct})_{2}$, tin(II) 2-ethylhexanoate, 2-ethylhexanoic acid tin(II) salt, 95\%, Aldrich Co. Poland) was used as received. Dichloromethane (anhydrous, $\geq 99.8 \%$, POCh, Gliwice, Poland), methanol (anhydrous, $99.8 \%$, POCh, Gliwice, Poland) and diethyl ether (anhydrous, $99.8 \%$, POCh, Gliwice, Poland) were used as received.

\section{Measurements}

The polymerization products were characterized in the DMSO- $\mathrm{d}_{6}$ solution by means of ${ }^{1} \mathrm{H}$ and ${ }^{13} \mathrm{C}$ NMR techniques (Varian $300 \mathrm{MHz}$ ). The FT-IR spectra in the $400-4,000 \mathrm{~cm}^{-1}$ range were measured from $\mathrm{KBr}$ pellets using Spectrum 1,000 spectrometer (Perkin-Elmer).

Number-average molecular weights $\left(M_{n}\right)$ and polydispersity indexes $\left(M_{w} / M_{n}\right)$ were measured using SEC-MALLS instrument composed of an 1,100 Agilent isocratic pump, autosampler, degasser, thermostatic box for columns, a photometer MALLS DAWN EOS (Wyatt Technology Corporation, Santa Barbara, CA) and differential refractometer Optilab Rex. ASTRA 4.90.07 software (Wyatt Technology Corporation) was used for data collecting and processing. Two $2 \mathrm{X}$ TSKgel MultiporeHXLcolumns were used for separation. The samples were injected as a solution in methylene chloride. The volume of the injection loop was $100 \mu \mathrm{L}$. Methylene chloride was used as a mobile phase at a flow rate of $0.8 \mathrm{~mL} \mathrm{~min}^{-1}$.

Mass spectrometric measurements were performed using the ultrafleXtreme ${ }^{\text {TM }}$ MALDI-TOF MS spectrometer (Bruker Daltonics, Fremont, CA) equipped with a pulsed $\mathrm{N}_{2}$ laser and a time-delayed extraction ion source. An acceleration voltage of $20 \mathrm{kV}$ was used. Mass spectra were obtained in the linear mode. The matrix 2[(4hydroxyphenyl)diazenyl] benzoic acid (HABA) was dissolved in THF or methylene chloride at a concentration equal to $10 \mathrm{mg} \mathrm{mL}^{-1}$ and mixed with a polymer sample in a 25:1 v/v ratio. NaI was added as a cationizing agent. The mixture was dried on stainless steel plate covered by the gold metal target.

\section{Polymerization procedure}

The polymeric materials were prepared using different molar ratios of initiator (genistein (Gns) to monomers ( $\varepsilon$-caprolactone (CL) or L-Lactide (LLA). The initiator/monomer feed ratios for the received polymers were: 1/25; 1/50; 1/75 (mol/ mol) for homopolymers of PLA and 1/25/25; 1/10/40;1/40/10 for copolymers of PLA/PCL denoted as Gns/PLA 25; Gns/PLA 50; Gns/PLA 75; Gns/PLA25/PCL25; Gns/PLA10/PCL40; Gns/PLA40/PCL10; respectively, where Gns = genistein; PLA $=$ poly(L-Lactide) and PCL $=$ poly( $\varepsilon$-caprolactone $)$. For the homopolymerization, dry Gns and LLA were accurately weighed and introduced into a $50 \mathrm{~mL}$ polymerization tube. The tube was then connected to a Schlenk line, where exhausting-refilling processes were repeated three times. The tube was immersed into an oil bath at $140{ }^{\circ} \mathrm{C}$ under argon atmosphere for $48 \mathrm{~h}$. After an appropriate 
time, the reaction products were cooled down, dissolved in dry $\mathrm{CH}_{2} \mathrm{Cl}_{2}$, precipitated twice from a cold diethyl ether and dried under vacuum for $72 \mathrm{~h}$.

NMR data for Gns/PLA 25

${ }^{1} \mathrm{H}$ NMR (DMSO-d 6 , $\left.300 \mathrm{MHz}, \delta_{\mathrm{H}}, \mathrm{ppm}\right) ; 8.31$ (s, H-1), 7.38-7.35 (dd, H-1', $\mathbf{4}^{\prime}, J_{1^{\prime}}$, $\left.2^{\prime}=8.5, J_{1^{\prime}, 4^{\prime}}=2.0,\right), 6.82-6.80\left(\mathrm{dd}, \mathbf{H}-2^{\prime}, \mathbf{3}^{\prime}, J_{1^{\prime}, 2^{\prime}}=8.5, J_{1^{\prime}, 3^{\prime}}=2.0\right), 6.38(\mathrm{~d}$, H-6, $\left.J_{6,5}=2.0\right), 6.24\left(\mathrm{~d}, \mathbf{H}-5, J_{6,5}=2.0\right), 5.18\left(\mathrm{q},-\mathrm{CH}\left(\mathrm{CH}_{3}\right)\right.$ - of PLA (a)), 4.97 $\left(\mathrm{q},-\mathrm{CH}\left(\mathrm{CH}_{3}\right)-\right.$ of PLA $\left.\left(\mathbf{a}^{\prime \prime}\right)\right), 4.18\left(\mathrm{q},-\mathrm{CH}\left(\mathrm{CH}_{3}\right)\right.$, end group of PLA $\left.\left(\mathbf{a}^{\prime}\right)\right), 1.45(\mathrm{~d}$, $-\mathrm{CH}_{3}$ of PLA $\left.\left(\mathbf{b}+\mathbf{b}^{\prime \prime}\right)\right), 1.27\left(\mathrm{~d},-\mathrm{CH}_{3}\right.$, end group of PLLA (b') (Fig. 1a and Fig. S-1, electronic supplementary material).

${ }^{13} \mathrm{C}-\mathrm{NMR}$ (DMSO-d $6,300 \mathrm{MHz}, \delta, \mathrm{ppm}$ ); ${ }^{13} \mathrm{C}-\mathrm{NMR}$ (DMSO-d $, 300 \mathrm{MHz}, \delta$, ppm); 181.12 (4), $173.98\left(\mathbf{c}^{\prime}\right), 171.14\left(\mathbf{c}^{\prime \prime}\right), 169.16(\mathbf{c}), 168.11\left(\mathbf{4}^{\prime}+\mathbf{5}+\mathbf{7}\right), 158.51$ (9), $153.90(\mathbf{2}), 131.15\left(\mathbf{2}^{\prime}+\mathbf{6}^{\prime}\right), 124.50\left(\mathbf{3}+\mathbf{1}^{\prime}\right), 115.02\left(\mathbf{3}^{\prime}+\mathbf{5}^{\prime}\right), 106.00(\mathbf{1 0})$, $98.92(\mathbf{6}), 93.36(\mathbf{8}), 68.64\left(\mathbf{a}+\mathbf{a}^{\prime \prime}\right), 65.56\left(\mathbf{a}^{\prime}\right), 16.43\left(\mathbf{b}+\mathbf{b}^{\prime}+\mathbf{b}^{\prime \prime}\right)$ (Figs. S-2 and $\mathrm{S}-3$, electronic supplementary material).

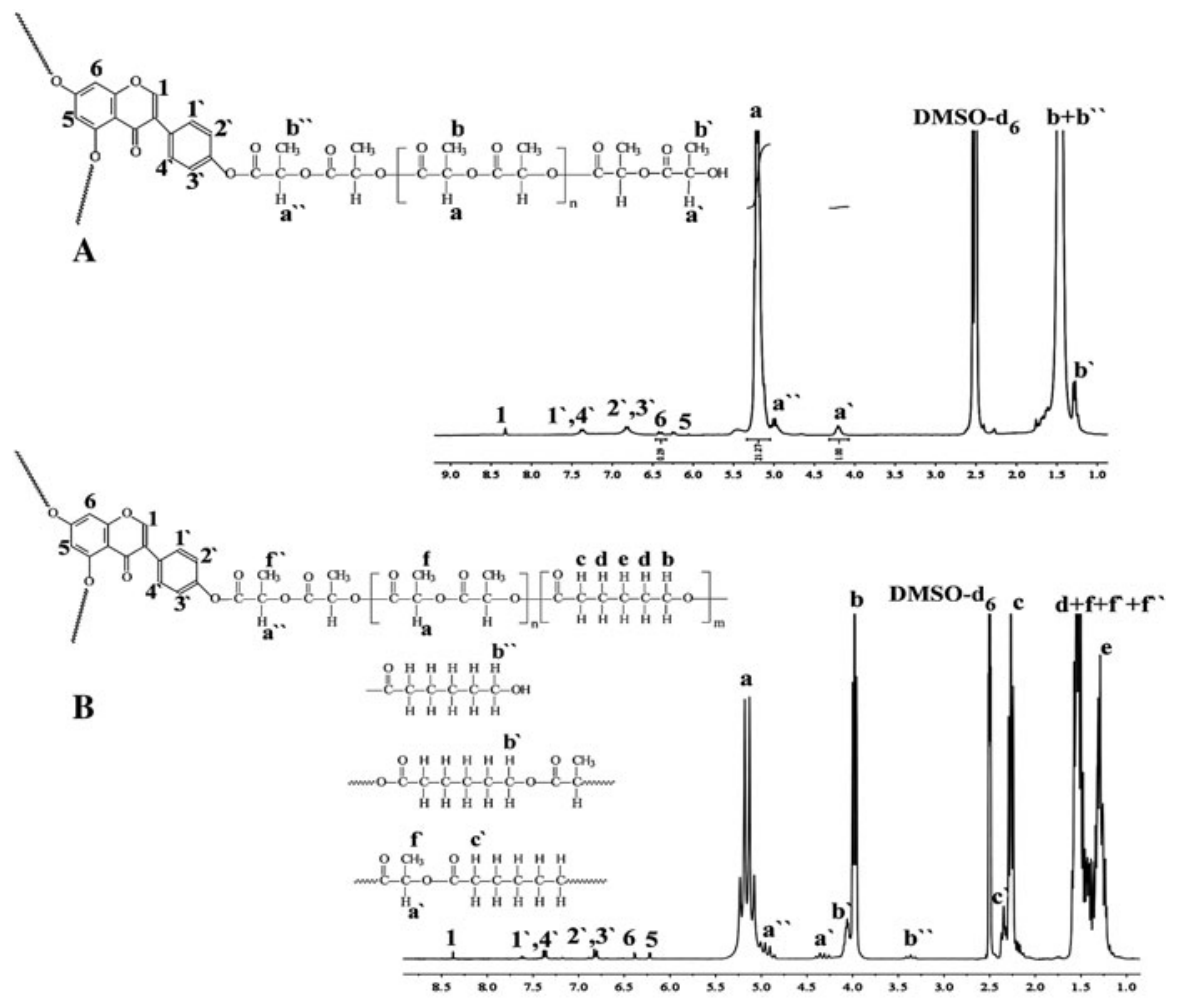

Fig. $1{ }^{1} \mathrm{H}$ NMR spectra of Gns/PLA 25 (a) and Gns/PLA25/PCL25 (b) 
FT-IR data for Gns/PLA 25

FT-IR $\left(\mathrm{KBr}, \mathrm{cm}^{-1}\right): 2,995\left(v_{\mathrm{as}} \mathrm{CH}_{3}\right), 2,947\left(v_{\mathrm{s}} \mathrm{CH}_{3}\right), 2,884(v \mathrm{CH}), 1,747\left({ }^{\circ} \mathrm{C}=\mathrm{O}\right)$, $1,451 \quad\left(\delta_{\mathrm{as}} \mathrm{CH}_{3}\right), \quad 1,378 \quad\left(\delta_{\mathrm{s}} \mathrm{CH}_{3}\right), \quad 1,368-1,360 \quad\left(\delta_{1} \mathrm{CH}+\delta_{\mathrm{s}} \mathrm{CH}_{3}\right), \quad 1,264$ $(\delta \mathrm{CH}+v \mathrm{COC}), 1,197\left(v_{\mathrm{as}} \mathrm{COC}+\mathrm{r}_{\mathrm{as}} \mathrm{CH}_{3}\right), 1,131\left(\mathrm{r}_{\mathrm{as}} \mathrm{CH}_{3}\right), 1,091\left(v_{\mathrm{s}} \mathrm{COC}\right), 1,045$ $\left(v \mathrm{C}-\mathrm{CH}_{3}\right), 952\left(\mathrm{rCH}_{3}+v \mathrm{CC}\right), 863(v \mathrm{C}-\mathrm{COO}), 754(\delta \mathrm{C}=0), 670(\gamma \mathrm{C}=\mathrm{O})$ (Fig. $\mathrm{S}-5$, electronic supplementary material).

For the copolymerization, dry Gns and LLA were accurately weighed and introduced into $50 \mathrm{~mL}$ polymerization tube. The tube was then connected to a Schlenk line, where exhausting-refilling processes were repeated three times. The tube was immersed into an oil bath at $140{ }^{\circ} \mathrm{C}$ under an argon atmosphere for $48 \mathrm{~h}$. After an appropriate time, the precise weight of CL and a catalytic amount of $\mathrm{Sn}(\mathrm{Oct})_{2}$ were added to the melted mixture and the exhausting-refilling process was carried out again. The polymerization tube was put into an oil bath at $110{ }^{\circ} \mathrm{C}$ under nitrogen atmosphere and cooled to room temperature after polymerization for $24 \mathrm{~h}$. The resulting products were dissolved in dry $\mathrm{CH}_{2} \mathrm{Cl}_{2}$, precipitated twice from a cold diethyl ether and dried under vacuum for $72 \mathrm{~h}$.

\section{NMR data for Gns/PLA25/PCL25}

${ }^{1} \mathrm{H}$ NMR (DMSO-d 6 , $\left.300 \mathrm{MHz}, \delta_{\mathrm{H}}, \mathrm{ppm}\right) ; 8.32$ (s, H-1), 7.38-7.35 (dd, H-1', $\mathbf{4}^{\prime}, J_{1^{\prime}}$, $\left.2^{\prime}=8.5, J_{1^{\prime}, 4^{\prime}}=2.0,\right), 6.82-6.79\left(\mathrm{dd}, \mathbf{H}-2^{\prime}, \mathbf{3}^{\prime}, J_{1^{\prime}, 2^{\prime}}=8.5, J_{1^{\prime}, 3^{\prime}}=2.0\right), 6.38(\mathrm{~d}, \mathbf{H}-6$, $\left.J_{6,5}=2.0\right), 6.21\left(\mathrm{~d}, \mathbf{H}-5, J_{6,5}=2.0\right), 5.19\left(\mathrm{q},-\mathrm{CH}\left(\mathrm{CH}_{3}\right)-\right.$ of PLA (a)), 4.94 (q, $-\mathrm{CH}\left(\mathrm{CH}_{3}\right)$ - of PLA $\left.\left(\mathbf{a}^{\prime \prime}\right)\right), 4.32\left(\mathrm{q},-\mathrm{CH}\left(\mathrm{CH}_{3}\right)\right.$ of PLA $\left.\left(\mathbf{a}^{\prime}\right)\right), 4.06\left(\mathrm{t},-\mathrm{CH}_{2} \mathrm{O}-\right.$ of PCL $\left.\left(\mathbf{b}^{\prime}\right)\right), 3.97\left(\mathrm{t},-\mathrm{CH}_{2} \mathrm{O}-\right.$ of PCL $\left.(\mathbf{b})\right), 3.31\left(\mathrm{t},-\mathrm{CH}_{\mathbf{2}} \mathrm{OH}\right.$, end group of PCL $\left.\left(\mathbf{b}^{\prime \prime}\right)\right), 2.32(\mathrm{t}$, $-\mathrm{CH}_{2} \mathrm{CH}_{2} \mathrm{C}(\mathrm{O})-$ of PCL $\left.\left(\mathbf{c}^{\prime}\right)\right), 2.26\left(\mathrm{t},-\mathrm{CH}_{2} \mathrm{CH}_{2} \mathrm{C}(\mathrm{O})-\right.$ of PCL $\left.(\mathbf{c})\right), 1.57-1.40$ (m, $-\mathrm{CH}_{2} \mathrm{CH}_{2} \mathrm{C}(\mathrm{O})-$ of PCL $(\mathbf{d})$ and $-\mathrm{CH}_{3}$ of PLA $\left.\left(\mathbf{f}+\mathbf{f}^{\prime}+\mathbf{f}^{\prime \prime}\right)\right), 1.29\left(\mathrm{t},-\mathrm{CH}_{2} \mathrm{CH}_{2} \mathrm{CH}_{2}-\right.$ of PCL (e) (Fig. 1b, Fig. S-1, electronic supplementary material).

${ }^{13}$ C-NMR (DMSO-d $\left.6,300 \mathrm{MHz}, \delta, \mathrm{ppm}\right) ; 181.14$ (4), 173.91 ('a'), 173.37 (h), $172.04\left(\mathbf{h}^{\prime}\right), 169.65(\mathbf{a}), 168.37\left(\mathbf{4}^{\prime}+\mathbf{5}+\mathbf{7}\right), 158.61(\mathbf{9}), 153.94(\mathbf{2}), 130.09\left(\mathbf{2}^{\prime}+\mathbf{6}^{\prime}\right)$, $124.77\left(\mathbf{3 , \mathbf { 1 } ^ { \prime }}\right), 115.01\left(\mathbf{3}^{\prime}+\mathbf{5}^{\prime}\right), 106.09(\mathbf{1 0}), 98.91(\mathbf{6}), 93.61(\mathbf{8}), 68.14\left(\mathbf{b}+\mathbf{b}^{\prime \prime}\right), 67.70$ $\left(\mathbf{b}^{\prime}\right), 64.42\left(\mathbf{e}^{\prime}\right), 63.43(\mathbf{e}), 61.08\left(\mathbf{e}^{\prime \prime}\right), 33.31(\mathbf{d}), 61.08\left(\mathbf{d}^{\prime}\right), 27.72(\mathbf{f}), 24.69(\mathbf{f}), 24.04(\mathbf{g})$, $16.46\left(\mathbf{c}+\mathbf{c}^{\prime}+\mathbf{c}^{\prime \prime}\right)$ (Figs. S-2 and S-4, electronic supplementary material).

FT-IR data for Gns/PLA25/PCL25

FT-IR $\left(\mathrm{KBr}, \mathrm{cm}^{-1}\right): 2,997\left(v_{\mathrm{as}} \mathrm{CH}_{3}\right), 2,949-2,945\left(v_{\mathrm{as}} \mathrm{CH}_{2}\right)\left(v_{\mathrm{s}} \mathrm{CH}_{3}\right), 2,865\left(v_{\mathrm{s}} \mathrm{CH}_{2}\right)$, $1,764 \quad(v \mathrm{C}=\mathrm{O}), \quad 1,457 \quad\left(\delta_{\mathrm{as}} \mathrm{CH}_{3}\right), \quad 1,348-1,387 \quad\left(\delta_{\mathrm{s}} \mathrm{CH}_{3}\right), \quad 1,368-1,360$ $\left(\delta_{1} \mathrm{CH}+\delta_{\mathrm{s}} \mathrm{CH}_{3}\right), 1,315-1,300\left(\delta_{2} \mathrm{CH}\right), 1,275\left(\mathrm{v}_{\mathrm{as}} \mathrm{COC}\right), 1,161\left(\mathrm{v}_{\mathrm{s}} \mathrm{COC}\right)$ (Fig. S-6, electronic supplementary material).

\section{Results and discussion}

The ROP homopolymerization of LLA was carried out in bulk in the presence of natural isoflavonoid Gns, identified as an angiogenesis inhibitor [19]. To obtain 
Table 1 Homopolymerization of LLA and copolymerization of CL and LLA initiated (co-initiated) by Gns; molecular characterization of the resulting polymers

\begin{tabular}{llllllll}
\hline Entry & {$[\mathrm{LLA}] /[\mathrm{CL}] /[\mathrm{I}]$} & Yield $(\%)$ & $\mathrm{DP}^{\mathrm{a}}$ & $\mathrm{DS}^{\mathrm{b}}$ & $M_{n(\mathrm{NMR})}^{\mathrm{c}}$ & $M_{n}^{\mathrm{d}}$ (SEC-MALLS) & $M_{\mathrm{w}} / M_{n}^{\mathrm{d}}$ \\
\hline Gns/PLA 25 & $25 / 0 / 1$ & 88 & 22.30 & 3.4 & 5,700 & 5,500 & 1.32 \\
Gns/PLA 50 & $50 / 0 / 1$ & 83 & 36.50 & 2.9 & 7,900 & 7,200 & 1.40 \\
Gns/PLA 75 & $75 / 0 / 1$ & 90 & 45.50 & 2.8 & 9,500 & 9,100 & 1.27 \\
Gns/PLA25/PCL25 & $25 / 25 / 1$ & 93 & 34.10 & 3.1 & 12,400 & 12,100 & 1.36 \\
Gns/PLA10/PCL40 & $10 / 40 / 1$ & 98 & 31.30 & 2.8 & 10,300 & 9,300 & 1.37 \\
Gns/PLA40/PCL10 & $40 / 10 / 1$ & 96 & 34.60 & 2.9 & 11,700 & 11,500 & 1.50 \\
\hline
\end{tabular}

Reaction conditions: nitrogen atmosphere, reaction temperature $-140{ }^{\circ} \mathrm{C}$ (for homopolymerization), $110^{\circ} \mathrm{C}$ (for copolymerization); L,L-Lactide (LLA), $\varepsilon$-caprolactone (CL), I initiator-genistein (Gns)

${ }^{a}$ DP: the average degree of polymerization determined by ${ }^{1} \mathrm{H}$ NMR analysis, calculated based on the area ratio of the terminal methine proton of PLA $(4.18 \mathrm{ppm})$ or methylene protons of PCL (3.31 ppm) to the internal methine proton of PLA (5.19 ppm) or methylene proton of PCL (3.97 ppm)

b $D S$ the average degree of substitution determined by ${ }^{1} \mathrm{H}$ NMR analysis, calculated based on the peak areas for the terminal methine proton of PLA (4.19 ppm) or methylene protons of PCL (3.31 ppm) and the benzyl proton of Gns (6.38 ppm)

${ }^{\mathrm{c}} M_{\mathrm{n}(\mathrm{NMR})}$ was determined by ${ }^{1} \mathrm{H}$ NMR spectroscopy

${ }^{\mathrm{d}} M_{\mathrm{n} \text { (SEC-MALLS) }}$ and $M_{\mathrm{w}} / M_{\mathrm{n}}$ were determined using SEC-MALLS instrument

LLA prepolymers with different molecular weights, the molar ratio of LLA and the initiator Gns was varied ([LLA $] /[\mathrm{I}]=25,50,75)$. The ${ }^{1} \mathrm{H}$ NMR spectrum of Gns/ PLA 25 is shown in Fig. 1a.

The major resonance signals $a$ and $b+b^{\prime}$ were attributed to the PLA chain, whereas signal $\mathrm{a}^{\prime}$ to the methine proton signal terminated by the hydroxyl end group. Furthermore, signal $\mathrm{a}^{\prime \prime}$ was assigned to the methine proton signal of PLA unit directly connected to the initiator molecule. The most important, the proton signals of phenyl and benzopyran-4-one rings of Gns (Fig. S-1, electronic supplementary material) were also detected with high resolution, indicating incorporation of Gns into the macromolecule (Fig. 1a) [21]. ${ }^{1} \mathrm{H}$ NMR analysis demonstrated that naturally occurring Gns successfully initiated ROP of LLA. An additional confirmation of the presence of Gns in the macromolecule is given by comparison of the ${ }^{13} \mathrm{C}$ NMR spectra of the resulting homopolymer and the pure initiator (Figs. S-2 and S-3, electronic supplementary material).

Based on the generally accepted conclusion, the number-average molecular weights determined by ${ }^{1} \mathrm{H}$ NMR spectroscopy $\left(M_{n \text { (NMR) }}\right)$ were calculated from the average chain length (DP) and average degree of substitution (DS) of the resulting homopolymers [22]. The calculation results as well as SEC-MALLS data are shown in Table 1.

The results revealed that the three PLA arms can be attached to the Gns initiator molecule, demonstrating that the three hydroxyl groups of Gns were effective initiation centers of ROP of LLA. Furthermore, it was noted that $M_{n}$ obtained by SEC-MALLS were similar to those calculated from ${ }^{1} \mathrm{H}$ NMR analysis and that 


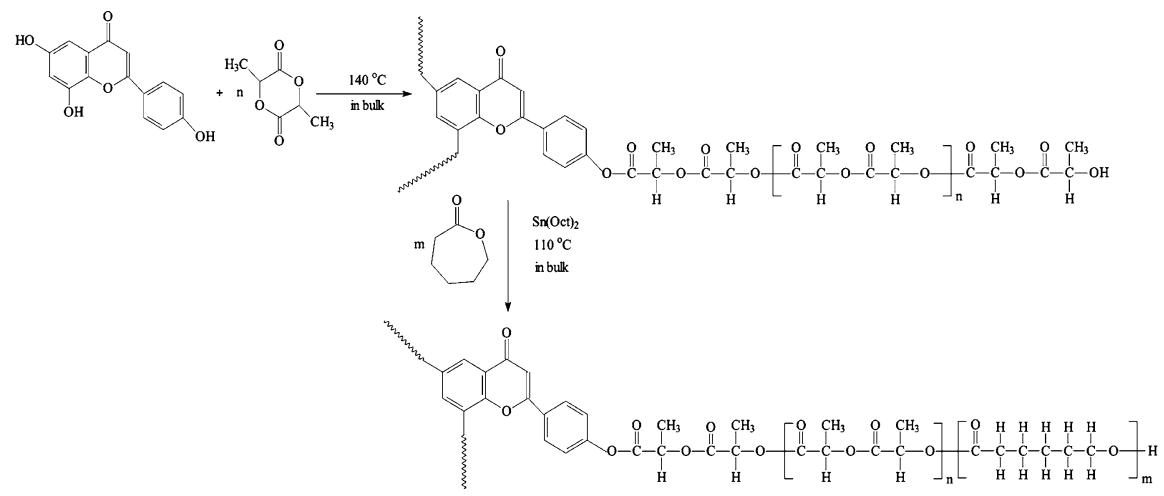

Scheme 1 Synthesis of homo- and copolymers

polymer materials with high yield and moderate molecular weight distribution were prepared using the natural initiator.

The hydroxyl end-capped PLAs with Gns core were then applied as macroinitiators of ROP of CL (Scheme 1). The copolymerization was carried out in bulk at moderate temperature around $110{ }^{\circ} \mathrm{C}$ to avoid transesterification [23, 24]. SECMALLS analysis was carried out for PLA macroinitiator and then for product copolymerization. The typical SEC-MALLS curves of the resulting products revealed a symmetrical elution peak with narrow polydispersity $\left(M_{w} / M_{n}\right.$, Table 1$)$. Furthermore, an expected shift to higher molar masses was observed for the PLA-rPCL copolymer when compared with PLA macroinitiator (Fig. 2; Table 1).

The ${ }^{1} \mathrm{H}$ NMR spectrum of Gns/PLA25/PCL25 is shown in Fig. 1b. The signals assigned to the phenyl and benzopyran-4-one protons rings of Gns may be clearly observed [as comparison see the ${ }^{1} \mathrm{H}$ NMR spectrum of the pure initiator (Fig. S-1,

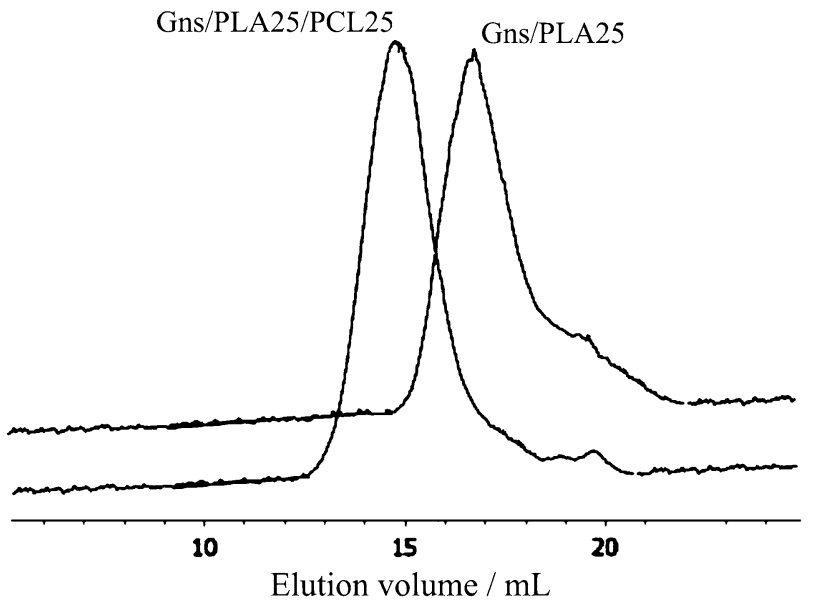

Fig. 2 SEC traces of the PLA macroinitiator and the corresponding PLA-r-PCL copolymer 


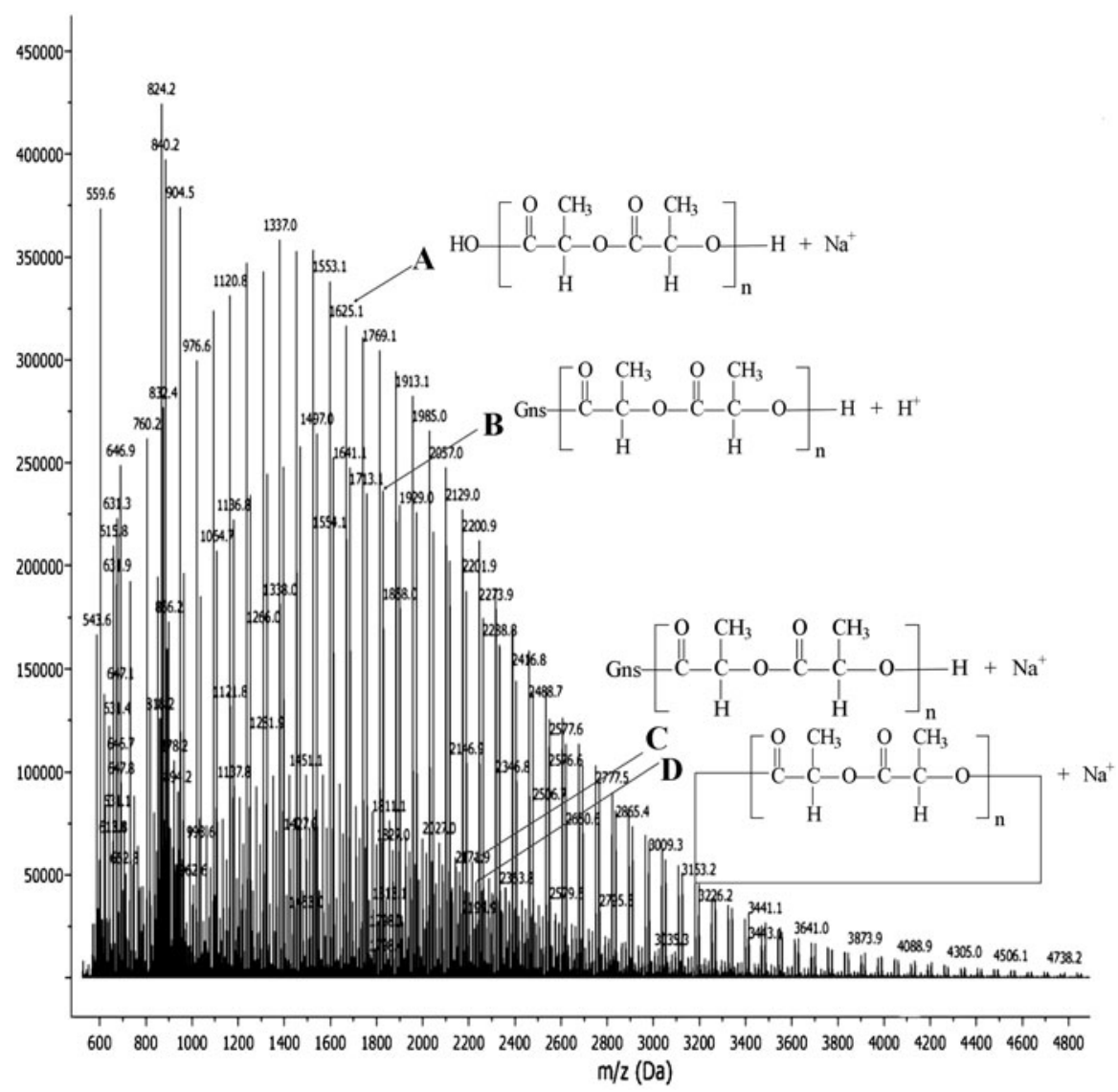

Fig. 3 MALDI-TOF MS spectrum of Gns/PLA 25

electronic supplementary material)]. Moreover, the presence of a new triplet signal assigned to methylene protons $\left(b^{\prime \prime}\right)$ indicated that the resulting copolymers were produced with PCL blocks as end groups and that the terminal hydroxyl groups of the macroinitiators effectively initiated the polymerization of CL. This occurrence is in accordance with our previous study [25]. Figure S-4 (electronic supplementary material) shows the ${ }^{13} \mathrm{C}$ NMR spectra of Gns/PLA25/PCL25 that additionally confirm the structure of the resulting copolymers. The number-average molecular weights, the average chain length as well as degree of substitution were also determined by ${ }^{1} \mathrm{H}$ NMR spectroscopy. The calculation results suggested a similar trend to that observed in the PLA system. The molecular weight distribution was also moderate and the number-average molecular weights obtained by SECMALLS analysis were similar to ${ }^{1} \mathrm{H}$ NMR calculations (Table 1).

Figure 3 shows the MALDI-TOF mass spectrum of PLA obtained from the homopolymerization of LLA initiated by Gns (Gns/PLA 25). 
The spectrum shows four main series of peaks. The first series corresponds to a PLA molecule terminating with one hydroxyl and one hydrogen end group (residual mass $41, \mathrm{Na}^{+}$adduct, A). The second series of peaks can be assigned to PLA terminating with Gns and hydrogen end groups (residual mass $271, \mathrm{H}^{+}$adduct, B). The third series, with smaller intensity, also corresponds to PLA terminating with Gns and hydrogen end groups, but with $\mathrm{Na}^{+}$adduct (residual mass 274, C), while the fourth weak series of peaks is consistent with macrocyclic polymers (residual mass $3, \mathrm{Na}^{+}$adduct, D).

In the mass spectrum in Fig. 3, two populations of chains were detected that is with even and odd number of LA repeating units. They were separated by 72 amu. The two populations can be explained as typical of LLA polymerization and intraand intermolecular transesterification reaction [25].

The MALDI-TOF mass spectrum result clearly demonstrates the presence of the Gns molecule in the macromolecule that indicates quite effective initiation properties of Gns in the ROP of LLA. The formation of the polymer chains terminated with hydroxyl and hydrogen end groups (series A, Fig. 3) might be explained by hydrolysis process that can be usually occurred during precipitation of the polymer (in this study methylene chloride and diethyl ether/water environment) or concerning MALDI-TOF MS measurements as a result of mixing of the polymer sample with the matrix materials [26, 27], whereas formation of macrocyclic subunits by an intramolecular transesterification that favorable appeared under polymerization conditions [23].

\section{Conclusions}

In summary, to the best of my knowledge, this is the first report that describes the homo- and copolymerization of cyclic esters initiated by the natural isoflavonoidgenistein. Polymerization in bulk produced polymeric materials with a moderate molecular weight up to $12,100[\mathrm{~g} / \mathrm{mol}]$ and yield as high as $98 \%$. Spectroscopic data have clearly indicated the incorporation of genistein into the macromolecule. Due to the use of non-toxic chemicals, the obtained results are promising for the synthesis of the star-shaped macromolecules and their application as drug carriers in pharmacy.

Acknowledgments The author is grateful for the financial support received from the Medical University of Warsaw.

Open Access This article is distributed under the terms of the Creative Commons Attribution License which permits any use, distribution, and reproduction in any medium, provided the original author(s) and the source are credited.

\section{References}

1. Albertsson AC, Varma IK (2003) Recent developments in ring opening polymerization of lactones for biomedical applications. Biomacromolecules 4(6):1466-1486 
2. Hu Z, Fan X, Wang H, Wang J (2009) Synthesis and characterization of biodegradable and biocompatible amphiphilic block copolymers bearing pendant amino acid residues. Polymer 50(17):4175-4181

3. Oh JK (2011) Polylactide (PLA)-based amphiphilic block copolymers: synthesis, self-assembly, and biomedical applications. Soft Matter 7(11):5096-5108

4. He Ch, Kim SW, Lee DS (2007) In situ gelling stimuli-sensitive block copolymer hydrogels for drug delivery. J Control Release 127(3):189-207

5. Broström J, Boss A, Chronakis IS (2004) Biodegradable films of partly branched poly(L-lactide)-copoly( $\varepsilon$-caprolactone) copolymer: modulation of phase morphology, plasticization properties and thermal depolymerization. Biomacromolecules 5(3):1124-1134

6. Wang F, Bronich TK, Kabanov AV, Rauh RD, Roovers J (2005) Synthesis and evaluation of a star amphiphilic block copolymer from poly( $\varepsilon$-caprolactone) and poly(ethylene glycol) as a potential drug delivery carrier. Bioconjugate Chem 16(2):397-405

7. Kikkawa Y, Abe H, Iwata T, Inoue Y, Doi Y (2002) Crystallization, stability, and enzymatic degradation of poly(L-lactide) thin film. Biomacromolecules 3(2):350-356

8. Persenaire O, Alexandre M, Degée P, Dubois P (2001) Mechanisms and kinetics of thermal degradation of poly( $\varepsilon$-caprolactone). Biomacromolecules 2(1):288-294

9. Meneghetti SP, Lutz PJ, Rein D (1999) Star-shaped polymers via anionic polymerization methods. In: Mishra MK, Kobayashi S (eds) Star and hyperbranched polymers, Marcel Dekker, New York, pp. $27-57$

10. Cameron DJA, Shaver MP (2011) Aliphatic polyester polymer stars: synthesis, properties and applications in biomedicine and nanotechnology. Chem Soc Rev 40:1761-1776

11. Oledzka E, Sobczak M (2012) Polymers in the pharmaceutical applications-natural and bioactive initiators and catalysts in the synthesis of biodegradable and bioresorbable polyesters and polycarbonates. In: Agbo EC (ed) Innovations in biotechnology, InTech, Croatia, pp. 139-160

12. Oledzka E, Sokolowski K, Sobczak M, Kołodziejski WL (2011) $\alpha$-Amino acids as initiators of $\varepsilon$ caprolactone and L, L-lactide polymerization. Polym Int 60(5):787-793

13. Wang J-L, Wang L, Dong Ch-M (2005) Synthesis, crystallization and morphology of star-shaped poly(E-caprolactone). J Polym Sci A Polym Chem 43:5449-5457

14. Dai X-H, Dong Ch-M, Fa H-B, Yan D, Wei Y (2006) Supramolecular polypseudorotaxanes composed of star-shaped porphyrin-cored poly( $\varepsilon$-caprolactone) and $\alpha$-cyclodextrin. Biomacromolecules 7:3527-3533

15. Hua Ch, Peng S-M, Dong Ch-M (2008) Synthesis and characterization of linear-dendron-like poly( $(\varepsilon-$ caprolactone)-b-poly(ethylene oxide) copolymers via the combination of ring-opening polymerization and click chemistry. Macromolecules 41:6686-6695

16. An SG, Cho GCh (2004) Synthesis and characterization of amphiphilic poly(E-caprolactone) star block copolymers. Macromol Rapid Comm 25(5):618-622

17. Cui Y, Tang X, Huang X, Chen Y (2003) Synthesis of the star-shaped copolymer of $\varepsilon$-caprolactone and L-lactide from a cyclotriphosphazene core. Biomacromolecules 4(6):1491-1494

18. Oledzka E, Kaliszewska D, Sobczak M, Raczak A, Nikel P, Kołodziejski W (2012) Synthesis and properties of a star-shaped poly( $\varepsilon$-caprolactone)-ibuprofen conjugate. J Biomat Sci Polym E 23(16):2039-2054

19. Doerge DR, Chang HC, Churchwell MI, Holder CL (2000) Analysis of soy isoflavone conjugation in vitro and in human blood using liquid chromatography-mass spectrometry. Drug Metab Dispos 28:298-307

20. Lamartiniere CA (2000) Protection against breast cancer with genistein: a compound of soy. Am J Clin Nutr 71(6):1705-1707

21. Kolodziejski W, Mazurek AP, Kasprzycka-Guttman T (2000) ${ }^{13} \mathrm{C}$ CP/MAS NMR study of a genistein/piperazine complex. Chem Phys Lett 328:263-269

22. Chang KY, Lee YD (2009) Ring-opening polymerization of $\varepsilon$-caprolactone initiated by the antitumor agent doxifluridine. Acta Biomater 5:1075-1081

23. Kricheldorf HR, Boettcher C, Tönnes KU (1992) Polylactones: 23. Polymerization of racemic and meso-D, Llactide with various organotin catalysts: stereochemical aspects. Polymer 33(13):2817-2824

24. Spassky N, Simic V, Montaudo MS, Hubert-Pfalzgraf LG (2000) Inter- and intramolecular ester exchange reactions in the ring-opening polymerization of (D, L-lactide using lanthanide alkoxide initiators. Macromol Chem Phys 201:2432-2440 
25. Sobczak M, Kolodziejski W (2009) Polymerization of cyclic esters initiated by carnitine and tin (II) octoate. Molecules 14:621-632

26. Morrison RT, Boyd RK (1976)Organic Chemistry. In: Baes CF, Mesmer RE (eds) The hydrolysis of cations. 6th edns. Wiley, New York, pp 112-123

27. Kricheldorf HR, Eggerstedt S (1999) Macrocycles, 6. MALDI-TOF mass spectrometry of tin-initiated macrocyclic polylactones in comparison to classical mass-spectroscopic methods. Macromol. Chem Phys 200(6):1284-1291 